\title{
LETTER
}

\section{Hyperoxic damage and the need for optimised oxygenation practices}

\author{
Rylan A Hayes*, Kiran Shekar and John F Fraser \\ See related viewpoint by Cornet et al., http://ccforum.com/content/17/2/313
}

Congratulations to Cornet and colleagues [1] for their article questioning the use of supplemental oxygen in medical emergencies. They raise the issue that although high-dose oxygen is the initial management for many conditions, data that hyperoxia may produce harmful effects continue to accumulate [1,2]. Additional to the poorer outcomes presented by the authors [1], increased mortality and morbidity are also seen in traumatic brain injury, asphyxiated neonates and cardiopulmonary bypass [2]. Clearly this is not only an issue for emergency care, but any area of medicine where supranormal oxygen tensions are experienced. In the critical care setting, use of extracorporeal life support devices such as extracorporeal membrane oxygenation for cardiorespiratory support may expose patients to unprecedented partial pressures of oxygen (even far above mechanical ventilation) $[3,4]$.

Current practice is largely based on optimal oxygenation being unknown and instead adopts the assumption that maximal oxygenation is of maximal benefit $[1,2]$. However, oxygen in excess to normal physiology has the potential to disrupt homeostasis and cause adverse effects. In order to establish best practice for oxygen supplementation - a practice deeply ingrained in current medical techniques - clinical outcomes and pathophysiological mechanisms for hyperoxic damage need to be delineated. The authors raise the ethical issue of randomized clinical trials to test hyperoxia outcomes versus normoxia (as everything to date is retrospective analysis of outcomes). Although these data would be valuable in considering change, we present animal models as a more appropriate initial study to test the effects of hyperoxia before progressing to clinical studies $[2,4,5]$.

\section{Competing interests}

The authors declare that they have no competing interests.

Published: 25 July 2013

\section{References}

1. Cornet AD, Kooter AJ, Peters MJ, Smulders YM: The potential harm of oxygen therapy in medical emergencies. Crit Care 2013, 17:313.

2. Hayes R, Shekar K, Fraser J: Is hyperoxaemia helping or hurting patients during extracorporeal membrane oxygenation? Review of a complex problem. Perfusion 2013, 28:184-193.

3. Fraser JF, Shekar K, Diab S, Dunster K, Foley SR, McDonald CI, Passmore M, Simonova G, Roberts JA, Platts DG, Mullany DV, Fung YL: ECMO - the clinician's view. ISBT Sci Series 2012, 7:82-88.

4. Fung YL, Diab S, Dunster K, Foley SR, McDonald CI, Passmore M, Platts D, Simonova G, Shekar K, Stewart D, Fraser JF: Extracorporeal lessons from sheep. ISBT Sci Series 2012, 7:92-95.

5. Shekar K, Fung YL, Diab S, Mullany D V, McDonald CI, Dunster KR, Fisquet S, Platts DG, Stewart D, Wallis SC, Smith MT, Roberts JA, Fraser JF: Development of simulated and ovine models of extracorporeal life support to improve understanding of circuit-host interactions. Crit Care Resusc 2012, 14:105-111.

doi:10.1186/cc12802

Cite this article as: Hayes RA, et al:. Hyperoxic damage and the need for optimised oxygenation practices. Critical Care 2013, 17:441.
*Correspondence: rylan.hayes@bigpond.com

Critical Care Research Group, Adult Intensive Care Services, The Prince Charles

Hospital, Rode Road, Chermside, Queensland, Australia 4032 